Review

\title{
Modern Propulsions for Aerospace-A Review
}

\author{
${ }^{1}$ Relly Victoria Petrescu, ${ }^{2}$ Raffaella Aversa, \\ ${ }^{3}$ Bilal Akash, ${ }^{4}$ Ronald Bucinell, ${ }^{5}$ Juan Corchado, \\ ${ }^{2}$ Antonio Apicella and ${ }^{1}$ Florian Ion Tiberiu Petrescu \\ ${ }^{1}$ ARoTMM-IFToMM, Bucharest Polytechnic University, Bucharest, (CE), Romania \\ ${ }^{2}$ Advanced Material Lab, Department of Architecture and Industrial Design, \\ Second University of Naples, 81031 Aversa (CE), Italy \\ ${ }^{3}$ Dean of School of Graduate Studies and Research, American University of Ras Al Khaimah, UAE \\ ${ }^{4}$ Union College, USA \\ ${ }^{5}$ University of Salamanca, Spain
}

Article history

Received: 12-04-2017

Revised: $18-04-2017$

Accepted: 25-04-2017

Corresponding Author: Florian Ion Tiberiu Petrescu ARoTMM-IFToMM, Bucharest Polytechnic University, Bucharest, (CE), Romania E-mail: scipub02@gmail.com

\begin{abstract}
A spacecraft propulsion is any method used to accelerate spacecraft and artificial satellites. There are several different methods, each with advantages and disadvantages, spacecraft propulsion being an active area of research. However, most current spacecraft are propelled by forcing a gas exits through the rear of the vehicle at high speed through supersonic nozzle of a rocket engine. All spacecraft are using chemical rockets (fuel or solid fuel) to launch, although some (such as Pegasus missiles and Space Ship One) are using air jet engines in the first step. Most satellites have simple chemical thrusters (often missiles mono) or missiles resistojet to maintain orbit. Soviet bloc satellites have used electric propulsion for decades and the new Western geo-orbital spacecraft begin using electric propulsion for orbit maintenance of north-south. There is a need increasingly of more new propulsion systems, modern, technology-based.
\end{abstract}

Keywords: Spacecraft Propulsion, Chemical Rockets, Jet Engines, Satellites, Electric Propulsion

\section{Introduction}

Propulsion, on an aircraft, is obtained by creating a force, called thrust, which results from the acceleration of a mass of air by a propeller (driven by a piston engine or a turboshaft engine), or by the combustion of an air/fuel mixture (turbojet engine or rocket engine). The power train, which usually includes one, two or four engines, is one of the main components of the aircraft. This characteristic is often used to classify aircraft: Mono, bi or quadrimo, bi or quadritoprop, mono, bi or quadrijet.

The single-flow turbojet engine, which appeared in the Second World War, has given rise to turboprop and turbofan derivatives (turbofan engines) used on almost all heavy or fast-moving aircraft (less than $800 \mathrm{~km} / \mathrm{h}$ ), civilian and military, as well as on fighter jets. There is also a hybrid between these two systems called "propfan".

At the beginning of the 21 st century, the propellerdriven piston engine remained the most widely used system in almost all light aircraft (ULMs, planes and light helicopters). It was supplanted by the turbine engine for heavy or rapid helicopters, civil and military.

The thrusters are classified below according to their dilution ratio: The proportion between the thrust resulting from the acceleration of cold air and hot air. This classification has the merit of showing that a single principle is used for propulsion, even if it is declined in different technologies. That is why this article includes the propeller-driven motor, the ramjet and the pulsoreactor, which, although they have not undergone significant development, are part of the continuity of the presentation.

\section{Materials and Methods}

The piston engine allowed the first powered flight. The engine of the 1903 Wright Flyer had 4 cylinders in line. Some of the first planes were equipped with rotary star engines: The crankshaft was fixed and the engine + propeller assembly was rotating. This solution improved cooling but created a gyroscopic torque that was 
detrimental to the aircraft's maneuverability. Military aircraft of the 1940s used water-cooled V-12 engines, such as the Rolls-Royce Merlin on the P-51 Mustang, or stationary two-row air-cooled 7- or 9-cylinder engines, the very famous R-2800 Double Wasp that equipped the P-47 Thunderbolt. Commercial aircraft of the 1950s were equipped with these star engines with up to four rows of 7 cylinders for the most powerful $(3,550 \mathrm{hp})$.

The development of the high-power piston engine for aeronautics was completed in the late 1950s with the arrival of the turbojet engine. At present, the piston engine is only equipped with light aircraft and some very light helicopters for recreation and sports (eg., Robinson R22).

The propeller transforms the mechanical energy of the engine into propulsive force. The crankshaft produces a propeller, which accelerates the air by about $10 \%$ on a cruise (if the plane flies at $200 \mathrm{~km} / \mathrm{h}$, the speed of the air behind the propeller is $220 \mathrm{~km} / \mathrm{h}$ ) more during the phase of acceleration on the ground and in climb. The thrust produced by the exhaust gases may be added to the traction produced by the propeller if the exhaust outlets are oriented correctly. The term "propellant exhaust pipes" is used. This system was almost systematically installed on all the hunters of the Second World War.

The propulsion efficiency is of the order of 0.75 to 0.87 as long as the peripheral speed (sum of the feed speed and the speed of rotation at the blade tip) remains below Mach 0.7. The increase in the speed and the power to be transmitted oblige to limit the diameter, to increase the number of blades and to vary the setting of the blades (not variable) in flight. The light aircraft have two-bladed propellers of 1.50 to $2 \mathrm{~m}$ in diameter, for powers of the order of 80 to $160 \mathrm{hp}$. The larger piston engines have 4-bladed propellers, sometimes 5 , with a diameter of up to $4.20 \mathrm{~m}$ (Chance Vought F4U Corsair, Pratt and Whitney R-4360). Some devices have even been equipped with counter-rotating propellers (Version PR.XIX of the Supermarine Spitfire).

On a turboshaft engine (Fig. 1), virtually all the energy produced by the combustion is recovered by the turbines and transformed into torque on the transmission shaft. Indeed, a residual thrust at the outlet of the nozzle would be detrimental to the maintenance of the hovering flight. The evacuation of the gases is therefore carried out through divergent nozzles, which slow down the gases at the outlet.

The energy recovered by the turbines serves to drive the compressor and, via a reducer, the main rotor of the helicopter. The latter is equivalent to a helix whose plane of rotation is horizontal.

The turboprop is a turbine engine whose turbine drives a propeller whose plane of rotation is vertical (Fig. 2). The turboprop is generally double-body, that is to say that it has two turbines at the output which make two coaxial shafts rotate (Turboprop, Wikipedia). The first turbine is connected to the compressor, called the "regeneration" compressor and the second turbine is connected to the "power" propeller. The turboprop has been difficult to develop because it combines the difficulties of the turbojet engine and the propeller. Its efficiency is higher than that of the turbojet engine, but its use is limited by the drop in propeller efficiency beyond Mach 0.7 and above 8,000 $\mathrm{m}$ of altitude. This is the optimal mode of propulsion for commercial airplanes over short distances (one hour flight time, $400 \mathrm{~km}$ ), when the duration of high altitude flight is too short for a jet aircraft to make the difference. Many regional airplanes, ATR 42 and ATR 72, are equipped with this.

The first turboprop in commercial service was the Protheus, from Bristol Siddeley, developed in 1945 and equipping the Bristol Britannia. The United States did not have a reliable turboprop engine until 1956, the Allison T56, which still equips the Lockheed C-130 Hercules military cargo planes.

The propulsion efficiency may exceed $80 \%$ at Mach 0.4. As propeller performance decreases rapidly with altitude, the turboprop operating area covers low-speed aircraft such as regional transport aircraft, military missions such as maritime patrol (ATL-2) and Military cargo planes to use short runways (eg., Airbus A400M Atlas).

The first turbo-jet engines built after the Second World War were "pure" single-flow and single-body turbojets: A single turbine was driving the compressor and the entire air flow was passing through the reactor body (Fig. 3). For reasons of compression efficiency, it became necessary to separate the compressor into two parts, low pressure and high pressure, rotating at different speeds. Single-flow turbofan engines were then developed: The first turbine actuated the HP compressor and the second the compressor BP.

The double-flow turbofan engine (see above) is not always double-body. Older generations had only one shaft to drive the BP and HP turbines. Today, doubleflow reactors typically have two or even three bodies in order to allow different rotational speeds for the BP and HP compressor stages and even the BP, MP and HP compressors for triple body models.

The single-flow turbojet engine was used on all types of aircraft developed from the end of the Second World War. Its low subsonic efficiency, as well as noise abatement standards, has gradually disappeared in favor of the dual-flow reactor for commercial aircraft. The maximum propulsion efficiency of $75 \%$ is obtained at speeds greater than Mach 1.5. It therefore continues to equip military aircraft (interceptors in particular) which require good speed performance at all altitudes, although dual-flow turbojets have also begun to replace many of them in this field of use. 


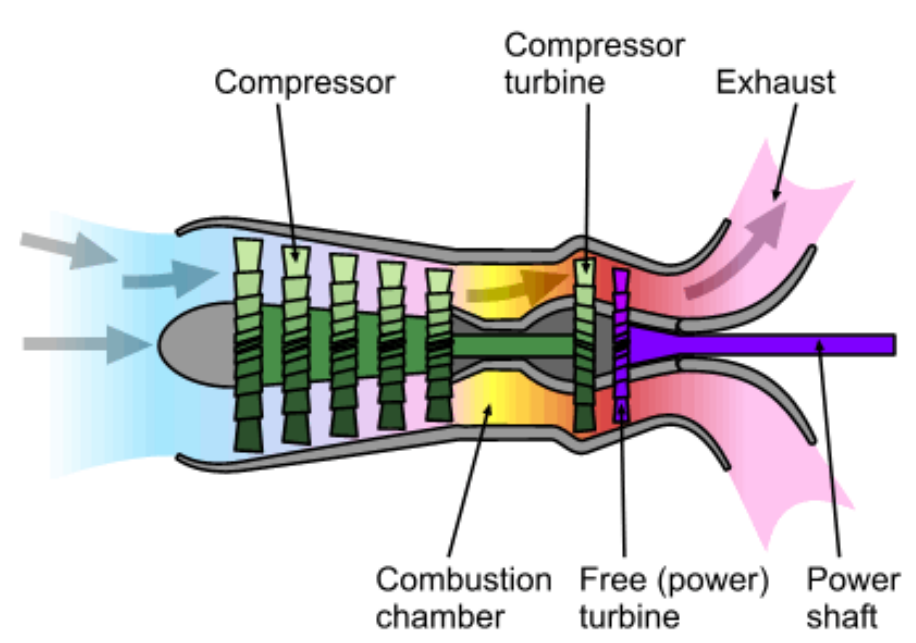

Fig. 1. Schematic diagram showing the operation of a simplified turboshaft engine; the compressor spool is shown in green and the free/power spool is in purple

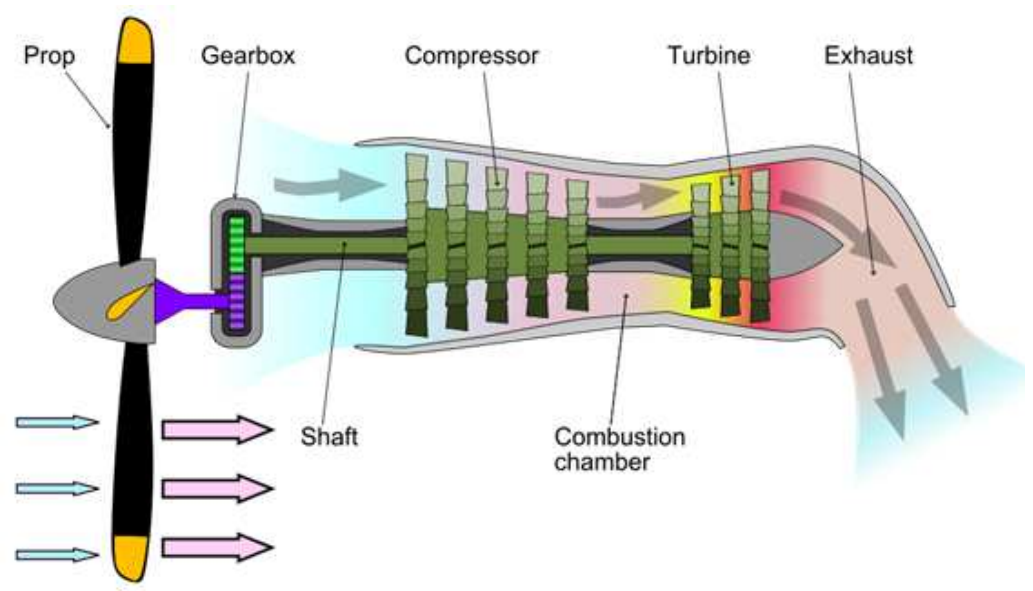

Fig. 2. Schematic diagram showing the operation of a turboprop engine

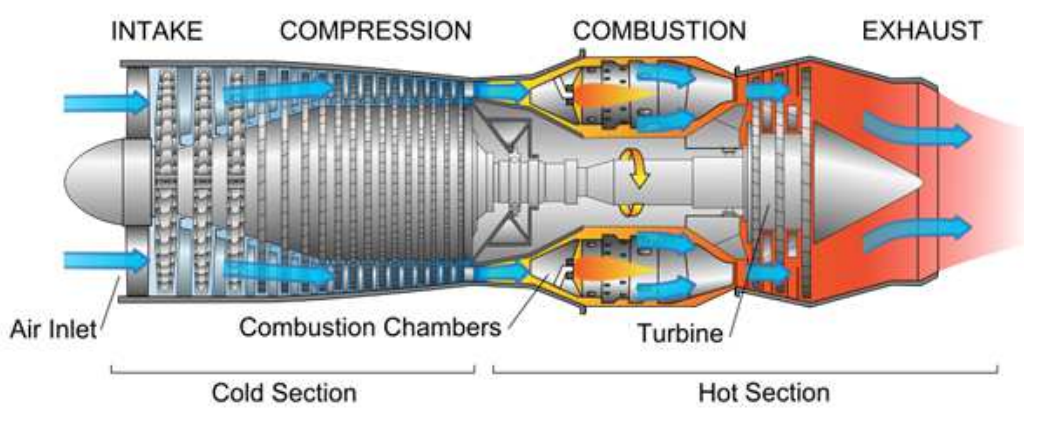

Fig. 3. Diagram of a typical gas turbine jet engine

The twin-jet turbojet engine, commonly referred to as "turbofan" or even "turbofan", combines a "pure" (singleflow) turbojet engine through which the primary flow, the hot flow, circulates to a paddlewheel called "blower" which drives the secondary concentric flow, the cold flow. The ratio of hot to cold flow is called the dilution ratio. The first dual-flow turbofan engines had a dilution ratio of 1.5: 1, but now there are 15: 1 levels. In a turbofan with a high dilution rate, at full power - Take-off, the blower produces about $80 \%$ of the total thrust produced by the engine (Fig. 4). 
The maximum propulsion efficiency of $70 \%$ is obtained towards Mach 0.8. It is proportional to the dilution rate. When an airplane flies at Mach 0.8, air does not circulate at the same speed over the entire structure and transonic phenomena can occur. As a result, speeds of the order of Mach 0.8-0.9 have become the norm for almost all civil transport aircraft, which explains the great development of this type of propulsion.

Derivatives of these engines, turbo blowers with gears and propfans, rely on dilution rates always higher to allow to obtain high thrusts and lower consumption.

The ramjet is a jet engine in which the air compression is ensured solely by the shape of the inner pipe and the relative wind force when the apparatus is moving in the air (Fig. 5). Unlike a turbojet, it does not have a compressor and only a throttle positioned in the middle of the main pipe creates pressure to ensure combustion. Its design is very simple because it looks like a tube and does not use any moving parts, hence the name "stato", for "static". On the other hand, it has the disadvantage of being able to operate only if its speed is high and therefore can't be used for an aircraft taking off autonomously.

This thruster has not experienced any substantial development on aircraft. On the other hand, it is used on air-to-air missiles, these being launched from an airplane whose own speed is used to start the ramjet. Its high specific consumption limits it to short-term uses. There was a time of hybrid engines, called "turbo-ramjets", which behave like conventional turbojet engines on takeoff and then gradually rocked in ramjet mode to realize flights at high speed and at high altitude. The best known example is the Pratt and Whitney J58, which fitted the American spy plane Lockheed SR-71 Blackbird.

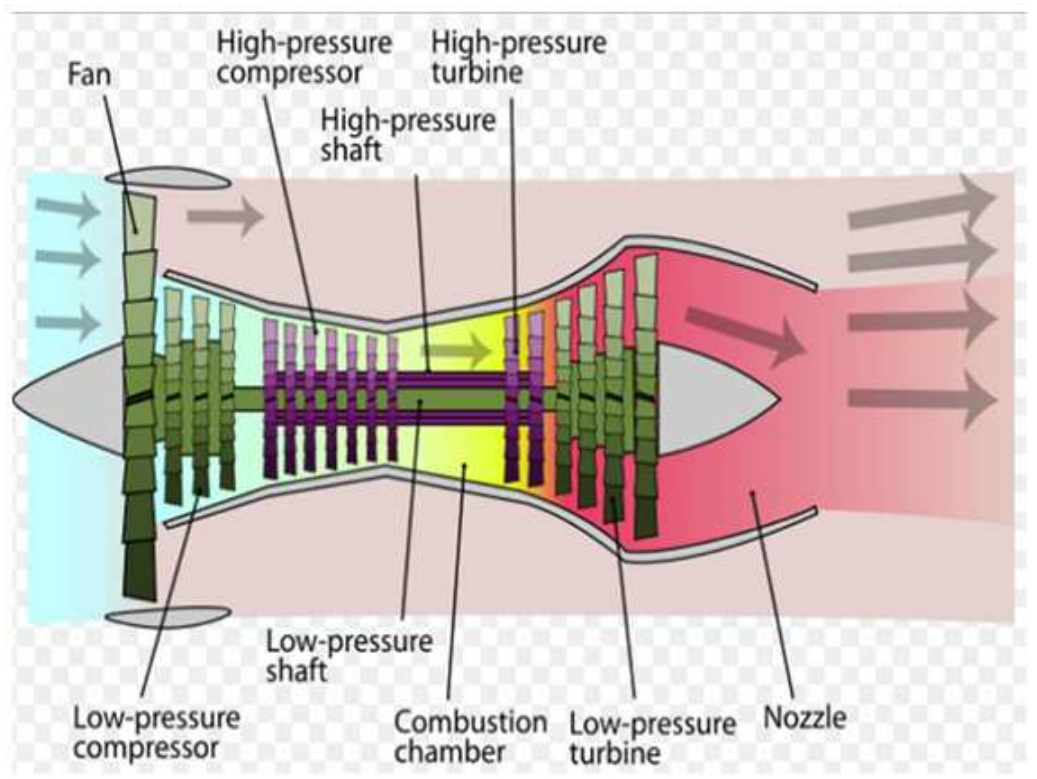

Fig. 4. A twin-jet turbojet engine

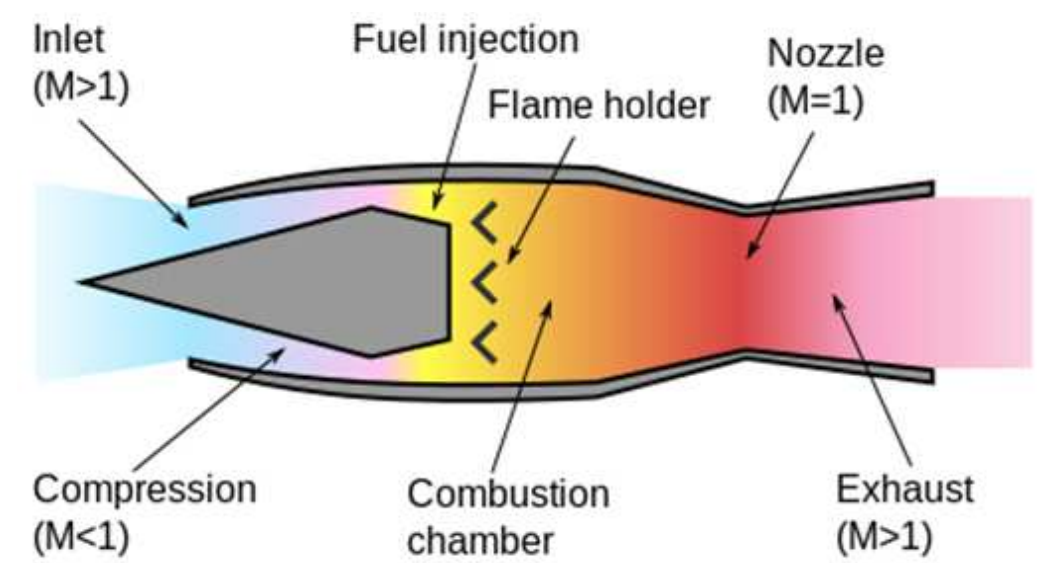

Fig. 5. Simple ramjet operation, with Mach numbers of flow shown 


\section{Results}

\section{Lockheed SR-71 Blackbird}

The Lockheed SR-71 Blackbird (Merle) is a version of the Lockheed A-12 Oxcart spy plane, built at least 32 for the US Air Force, which was used it mainly from 1968 to 1990 (Fig. 6).

Also known as "Habu" (named after a black snake living on some of Japan's islands, including Okinawa, where a detachment was based), the SR-71 retained the unique silhouette and extraordinary performance of the A-12, but was distinguished by specific recognition sensors and the presence of a second crew member responsible for implementing them.

The development of the SR-71 began in 1962 on the basis of the A-12, which had just made its first flight (Crickmore, 1997; Donald, 2003; Goodall, 2003; Graham, 2002; Jenkins, 2001; Landis and Dennis, 2005). Destined for the USAF, the SR-71 had to be able to carry out its mission of reconnaissance without having to pass vertically its objective, unlike the A-12. The first flight of this version took place on December 22, 1964. Starting in March 1968, the first SR-71s were deployed on the Kadena base in Okinawa, replacing the A-12s. The first operational mission took place on 21 March over Vietnam.

The SR-71 was used throughout the Cold War for surveillance and photographic espionage. In particular, he photographed all the secret sites of the USSR and more than 1,000 missiles were fired at him on these occasions without ever reaching it. Soviet missiles were not more than $2,200 \mathrm{~km} / \mathrm{h}$, but in flight, the aircraft almost never dropped below the $2,400 \mathrm{~km} / \mathrm{h}$ mark, Mach 2. Missions still remains a military secret, although some photos taken by the SR-71 have been declassified. Most of the SR-71s were based at Beale's base in California, but other bases, such as Kadena and Mildenhall, were also used.

The development by the United States of increasingly numerous and increasingly accurate military observation satellite networks has made the aircraft less and less competitive.

It is true that the SR-71's operations required extensive logistics, including a fleet of specialized refueling aircraft, the $\mathrm{KC}-135 \mathrm{Q}$, capable of supplying JP-7 special fuel, which was only used by the Blackbird. The SR-71s were generally fueled in high altitude flying after a Mach 3 speed peak, which allowed the airplane structure to heat up and expand, thereby ensuring leak-tightness of the tanks. The SR-71 was retired in January 1990. However, in September 1994, the US Congress voted a $\$ 100$ million budget to allow the reactivation of three SR-71s. These aircraft were returned to service from 1995 to 1998 . The last flight of an SR-71 took place in October 1999: It was a research flight on behalf of NASA.

Some argue that the Blackbird was, in fact, replaced by the hypothetical SR-91 Aurora or the Northrop B-2 Spirit whose official subsonic performance would be disinformation. However, if the Aurora program remains very obscure, the aerodynamic configuration of the B-2 prevents it from being supersonic. To compare with the SR-71 that easily surpassed Mach 3 and carried out its missions at speeds higher than Mach 2.8.

No aircraft was officially intercepted during the missions carried out, the high speed and high ceiling of the aircraft making such an event extremely unlikely. To train for the interception of the Soviet MiG-25, the Dassault Mirage F1 of the air base 115 Orange-Caritat had to try to intercept "several times" of the American SR-71 coming from the United Kingdom. "The black plane crosses France from the north to the south at Mach 2.8. The only possibility to intercept it is to take off two Orange planes as the aircraft approaches the French coasts on the Dieppe side! (...) The firing window is extremely narrow and does not exceed a few seconds. "In fact, it does not appear that the F1C ever managed to" kill "a Blackbird.

\section{The Saber (or Sabre) Engine}

The Saber (or Sabre) engine is a hybrid between aerobic engine and rocket engine. The engine is designed to be operated at Mach speed 5 and at an altitude of 26 $\mathrm{km}$. This engine uses on-board liquid hydrogen and oxygen from the air until the Skylon reaches Mach 5 and then use liquid oxygen embedded in the final phase of the ascent to orbit (Fig. 7), (Skylon, Wikipedia).

The function of the SABER is to use as many components of the rocket engine as possible for use by an aerobic engine. The first challenge is to increase the air pressure at the inlet of the combustion chamber to that of a rocket engine. In the concept of the Liquid Air Cycle Engine (LACE), the incoming air passes through a heat exchanger that uses liquid hydrogen to liquefy the air. From there, a pump can increase the air pressure to the desired value. The hot hydrogen is then burned in the combustion chamber with the high-pressure air.

An obvious disadvantage of LACE is that, given the heat capacity of the refrigerant (liquid hydrogen at 20 $\mathrm{K}$ ), it takes about 8 times more liquid hydrogen to liquefy a given mass of air than is needed To burn this same quantity of air under stoichiometric conditions.

The hydrogen-rich gas at the outlet of the nozzle still has a sufficiently high velocity to retain an advantage (specific pulse of 600 to $1,000 \mathrm{~s}$ ) compared to conventional rocket motors (Isp of less than 500 s). However, it remains an interest to use this surplus hydrogen.

SABER draws inspiration from LACE, while reducing its hydrogen consumption by $30 \%$ in several ways. In the case of LACE, hydrogen is simply used to 
liquefy incoming air. However, the energy gained by heating the hydrogen is much higher than that required to ensure the operation of the air compressor (liquid). The flow of hot hydrogen is therefore a waste of energy since the work that it could produce is not used.

In fact, the passage of air from the gaseous state to the liquid state also represents a loss of energy because part of the energy (latent heat) is wasted without Has an increase in density (and thus of pressure) of the air during its change of state.

The SABER pre-cooler only intensely cools the air (up to- $140{ }^{\circ} \mathrm{C}$ ) while keeping it in the gaseous state, which reduces the required hydrogen flow, while heating hydrogen sufficiently To transfer enough energy to the air turbocharger (this time in the gaseous state). The presence of the air in a single state makes it possible to dispense with capacitor, necessary to the LACE and the pressure of the air at the inlet of the combustion chamber remains high: About 102 bars.

In the SABER, helium serves as a refrigerant, providing an additional barrier between fuel and oxidizer and avoiding excessive embrittlement of the engine mechanics. Also, the hot gases of a pre-burner heat the helium in a heat exchanger when the vehicle is flying at speeds of less than Mach 5. Thus, the main turbine always operates under the same conditions and avoids the problems associated with the loss of efficiency of heat exchange at low speeds (the engine does not know how fast it is flying).

In addition, some of the unburned hydrogen is diverted to feed a ramjet that surrounds the main engine. Indeed, the amount of air passing through the engine is inversely proportional to the speed of the Skylon (Fig. 8 ). The ramjet is thus used optimally only between Mach 3 and Mach 3.5 and beyond, the main engines of the SABER provide thrust (Skylon, Wikipedia).

The SABER thermodynamic cycle uses relatively common components in the aerospace and astronautics industry.

The only completely new part is the lightweight, compact and powerful heat exchangers that SABER needs. A $9 \%$ scale model of the critical part of the engine, the pre-cooler, consisting of two separate heat exchangers (named HX1 and HX2), was built by Reaction Engines Limited and will be tested Throughout the summer of 2011 (Petrescu and Petrescu, 2011; 2012; 2013a; 2013b; 2013c).

Skylon is a design for a single-stage-to-orbit space plane by the British company Reaction Engines Limited (REL), using SABRE, a combined-cycle, air-breathing rocket propulsion system, potentially reusable for 200 flights. In paper studies, the cost per kilogram of payload carried to low Earth orbit in this way is hoped to be reduced from the current $£ 1,108 / \mathrm{kg}$ (as of December 2015), including research and development, to around $£ 650 / \mathrm{kg}$, with costs expected to fall much more over time after initial expenditures have amortised.
In 2004, the developer estimated the total lifetime cost of the programme to be about $\$ 12$ billion (Skylon, From Wikipedia).

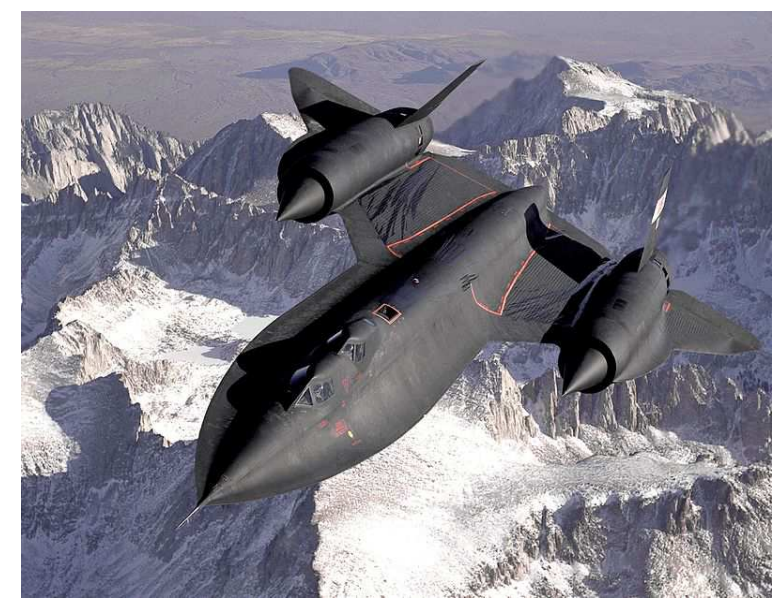

Fig. 6. Lockheed SR-71 Blackbird

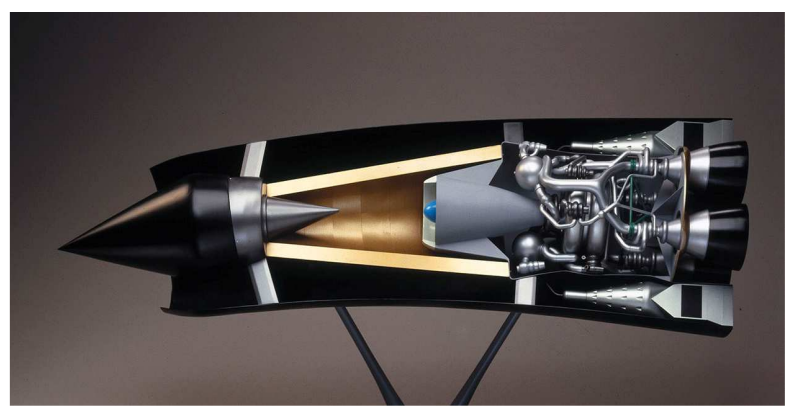

Fig. 7. The Saber (or Sabre) engine is a hybrid between aerobic engine and rocket engine

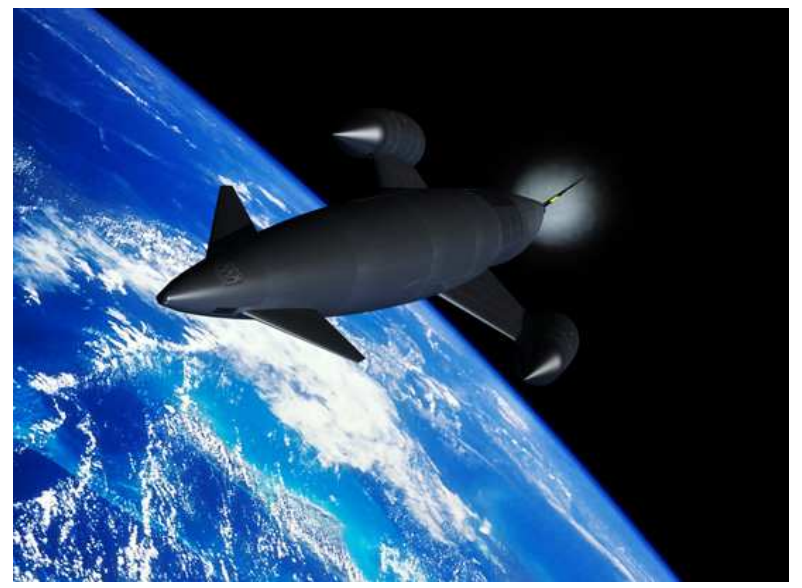

Fig. 8. Skylon is a design for a single-stage-to-orbit spaceplane by the British company Reaction Engines Limited (REL), using SABRE, a combined-cycle, air-breathing rocket propulsion system 


\section{Discussion}

Propulsion, on an aircraft, is obtained by creating a force, called thrust, which results from the acceleration of a mass of air by a propeller (driven by a piston engine or a turboshaft engine), or by the combustion of an air/fuel mixture (turbojet engine or rocket engine). The power train, which usually includes one, two or four engines, is one of the main components of the aircraft. This characteristic is often used to classify aircraft: Mono, bi or quadrimo, bi or quadritoprop, mono, bi or quadrijet.

The single-flow turbojet engine, which appeared in the Second World War, has given rise to turboprop and turbofan derivatives (turbofan engines) used on almost all heavy or fast-moving aircraft (less than $800 \mathrm{~km} / \mathrm{h}$ ), civilian and military, as well as on fighter jets. There is also a hybrid between these two systems called "propfan".

SABER draws inspiration from LACE, while reducing its hydrogen consumption by $30 \%$ in several ways. In the case of LACE, hydrogen is simply used to liquefy incoming air. However, the energy gained by heating the hydrogen is much higher than that required to ensure the operation of the air compressor (liquid). The flow of hot hydrogen is therefore a waste of energy since the work that it could produce is not used.

In fact, the passage of air from the gaseous state to the liquid state also represents a loss of energy because part of the energy (latent heat) is wasted without Has an increase in density (and thus of pressure) of the air during its change of state.

The SABER pre-cooler only intensely cools the air (up to- $140{ }^{\circ} \mathrm{C}$ ) while keeping it in the gaseous state, which reduces the required hydrogen flow, while heating hydrogen sufficiently To transfer enough energy to the air turbocharger (this time in the gaseous state). The presence of the air in a single state makes it possible to dispense with capacitor, necessary to the LACE and the pressure of the air at the inlet of the combustion chamber remains high: About 102 bars.

In the SABER, helium serves as a refrigerant, providing an additional barrier between fuel and oxidizer and avoiding excessive embrittlement of the engine mechanics. Also, the hot gases of a pre-burner heat the helium in a heat exchanger when the vehicle is flying at speeds of less than Mach 5. Thus, the main turbine always operates under the same conditions and avoids the problems associated with the loss of efficiency of heat exchange at low speeds (the engine does not know how fast it is flying).

\section{Conclusion}

Propulsion, on an aircraft, is obtained by creating a force, called thrust, which results from the acceleration of a mass of air by a propeller (driven by a piston engine or a turboshaft engine), or by the combustion of an air/fuel mixture (turbojet engine or rocket engine).

The turboprop is a turbine engine whose turbine drives a propeller whose plane of rotation is vertical.

The Lockheed SR-71 Blackbird (Merle) is a version of the Lockheed A-12 Oxcart spy plane, built at least 32 for the US Air Force, which was used it mainly from 1968 to 1990 . The development of the SR-71 began in 1962 on the basis of the A-12, which had just made its first flight.

The Saber (or Sabre) engine is a hybrid between aerobic engine and rocket engine. The engine is designed to be operated at Mach speed 5 and at an altitude of 26 $\mathrm{km}$. This engine uses on-board liquid hydrogen and oxygen from the air until the Skylon reaches Mach 5 and then use liquid oxygen embedded in the final phase of the ascent to orbit. Skylon is a design for a single-stageto-orbit space plane by the British company Reaction Engines Limited (REL), using SABRE, a combinedcycle, air-breathing rocket propulsion system, potentially reusable for 200 flights.

\section{Author's Contributions}

All the authors contributed equally to prepare, develop and carry out this manuscript.

\section{Ethics}

Authors declare that are not ethical issues that may arise after the publication of this manuscript. This article is original and contains unpublished material.

\section{References}

Crickmore, P.F., 1997. Lockheed's blackbirds-A-12, YF12 and SR-71A. Wings Fame, 8: 30-93.

Donald, D., 2003. Lockheed's blackbirds: A-12, YF-12 and SR-71". Black Jets. AIRtime.

Goodall, J., 2003. Lockheed's SR-71 "Blackbird" Family. 1st Edn., Aerofax/Midland Publishing, Hinckley, UK.

Graham, R.H., 2002. SR-71 Blackbird: Stories, Tales and Legends. 1st Edn., Zenith Imprint, North Branch, Minnesota, ISBN-10: 1610607503.

Jenkins, D.R., 2001. Lockheed Secret Projects: Inside the Skunk Works. 1st Edn., Zenith Imprint, Publishing Company, ISBN-10: 1610607287.

Landis, T.R. and R.J. Dennis, 2005. Lockheed Blackbirds. 1st Edn., Specialty Press, North Branch, ISBN-10: 1580070868, pp: 104.

Petrescu, R.V. and F.I. Petrescu, 2013a. Lockheed Martin. 1st Edn., CreateSpace, pp: 114.

Petrescu, R.V. and F.I. Petrescu, 2013b. Northrop. 1st Edn., CreateSpace, pp: 96.

Petrescu, R.V. and F.I. Petrescu, 2013c. The Aviation History or New Aircraft I Color. 1st Edn., CreateSpace, pp: 292. 
Relly Victoria Petrescu et al. / Journal of Aircraft and Spacecraft Technology 2017, 1 (1): 1.8 DOI: 10.3844/jastsp.2017.1.8

Petrescu, F.I. and R.V. Petrescu, 2012. New Aircraft II. 1st Edn., Books On Demand, pp: 138.

Petrescu, F.I. and R.V. Petrescu, 2011. Memories about Flight. 1st Edn., CreateSpace, pp: 652.
Skylon (spacecraft) From Wikipedia, the free encyclopedia.

https://en.wikipedia.org/wiki/Skylon_(spacecraft)

Turboprop from Wikipedia, the free encyclopedia. https://en.wikipedia.org/wiki/Turboprop 